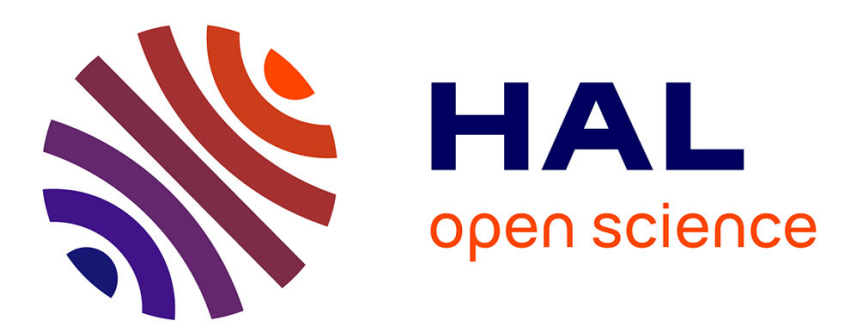

\title{
DNA condensation by an oxidizable cationic detergent. Interactions with lipid vesicles
}

David Llères, Emmanuel Dauty, Jean-Paul Behr, Yves Mély, Guy Duportail

\section{To cite this version:}

David Llères, Emmanuel Dauty, Jean-Paul Behr, Yves Mély, Guy Duportail. DNA condensation by an oxidizable cationic detergent. Interactions with lipid vesicles. Chemistry and Physics of Lipids, 2001, 111 (1), pp.59-71. 10.1016/S0009-3084(01)00147-5 . hal-03027038

\section{HAL Id: hal-03027038 \\ https://hal.science/hal-03027038}

Submitted on 26 Nov 2020

HAL is a multi-disciplinary open access archive for the deposit and dissemination of scientific research documents, whether they are published or not. The documents may come from teaching and research institutions in France or abroad, or from public or private research centers.
L'archive ouverte pluridisciplinaire HAL, est destinée au dépôt et à la diffusion de documents scientifiques de niveau recherche, publiés ou non, émanant des établissements d'enseignement et de recherche français ou étrangers, des laboratoires publics ou privés. 


\title{
DNA condensation by an oxidizable cationic detergent. Interactions with lipid vesicles
}

\author{
David Lleres a, Emmanuel Dauty ${ }^{\mathrm{b}}$, Jean-Paul Behr ${ }^{\mathrm{b}}$, Yves Mély a, \\ Guy Duportail ${ }^{\mathrm{a}, *}$ \\ a Laboratoire de Pharmacologie et Physicochimie des Interactions Cellulaires et Moléculaires, UMR 7034 du CNRS, \\ 67401 Illkirch Cedex, France \\ b Laboratoire de Chimie Génétique, UMR 7514 du CNRS, Faculté de Pharmacie, Université Louis Pasteur, BP 24, \\ 67401 Illkirch Cedex, France
}

Received 14 December 2000; accepted 03 April 2001

\begin{abstract}
Cationic amphiphile-mediated delivery of plasmid DNA is the non-viral gene transfer method most often used. In the present work, we considered a new cysteine-detergent, ornithinyl-cysteinyl-tetradecylamide $\left(\mathrm{C}_{14}-\mathrm{CO}\right)$, able to convert itself, via oxidative dimerization, into a cationic cystine-lipid. By using fluorescence techniques, we first characterized the structure of complexes of plasmid DNA with $\mathrm{C}_{14}-\mathrm{CO}$ molecules either kept as monomers, or oxidized into dimers. Both forms are able to condense DNA, with the formation of hydrophobic micelle-like domains along the DNA chain. Domains with a larger molecular order were obtained with dimeric $\mathrm{C}_{14}-\mathrm{CO} / \mathrm{DNA}$ complexes. In a second step, the interactions of these complexes with lipid vesicles considered as membrane models were investigated. In the presence of vesicles, we observed a decondensation of the DNA involved in complexes obtained with $\mathrm{C}_{14}$-CO monomers. With anionic vesicles, the DNA is released into the bulk solution, while with neutral vesicles, it remains bound to the vesicles via electrostatic interactions with inserted $\mathrm{C}_{14}$ - $\mathrm{CO}$ molecules. In sharp contrast, the complexes with $\mathrm{C}_{14}$-CO dimers are unaffected by the addition of either neutral or anionic vesicles and show no interaction with them. These results may partly explain the low transfection efficiency of these complexes at the \pm charge ratios used in this study. (C) 2001 Elsevier Science Ireland Ltd. All rights reserved.
\end{abstract}

Keywords: DNA condensation; Cationic detergents; Non-viral vectors; Transfection; Lipid vesicles

* Corresponding author. Tel.: + 33-390244260; fax: + 33390244312.

E-mail address: duportai@aspirine.u-strasbg.fr (G. Duportail).

\section{Introduction}

Gene therapy is based on the use of nucleic acids (plasmids, oligonucleotides) as therapeutic agents for the treatment of genetic disorders (myopathy, cystic fibrosis...), cancer and infectious diseases such as AIDS. As nucleic acids hardly 
cross cell membranes, the feasibility of gene therapy depends strongly on the use of vectors or vehicles which could deliver genetic material into a target cell with minimum toxicity. Presently, the major gene transfer strategies are based on the use of viral or non-viral vectors. Viral vectors show high gene transfer efficiency, but raise safety concerns and are immunogenic. These problems can be circumvented by using non-viral vectors like cationic liposomes (Miller, 1998), or cationic polymers such as polyethylenimine (PEI) (Godbey et al., 1999), polylysine and dendrimers (Tang and Szoka, 1997). However, the complexes formed between these molecules and DNA show a limited gene transfer efficiency in vivo. This is in part linked to the propensity of complexes to aggregate into particles larger than $1 \mu \mathrm{m}$, thus limiting their ability to cross membranes and diffuse through tissues and capillary vessels (Watts and Marsh, 1992; Zabner et al., 1995; Lasic, 1997). Aggregation may be overcome by the use of cationic detergents since it has been shown, for instance, that $\mathrm{CTAB}$ is able to condense isolated DNA molecules (Mel'nikov et al., 1995a). In such complexes, the electrostatic interaction between the detergent polar heads and the DNA phosphate groups is followed by a cooperative hydrophobic assembly of the lipophilic chains, leading to micelle-like structures (Mel'nikov et al., 1995b, 1997). At least at $( \pm)$ charge ratios lower than 1 , these complexes bear a negative surface charge which precludes aggregation. However, we have shown previously (Clamme et al., 2000) that, upon addition to cells, CTAB/DNA complexes are trapped on the external face of the plasma membrane. This feature may constitute a major limiting step in transfection. In fact, interaction of the complexes with the plasma membrane leads to opening of the micelle-like domains and incorporation of CTAB molecules into the lipid bilayer. In contrast, interaction with anionic vesicles that mimic the cytoplasmic facing leaflet leads to rapid DNA release, in agreement with the high transfection efficiency observed for DNA bound to vesicles composed of neutral lipids and cationic detergents (Pinnaduwage et al., 1989). In this case, the detergents are thought to destabilize the endosomal membrane and induce DNA release into the cytoplasm.
With these considerations in mind, it was appealing to try to combine the respective favourable features of cationic detergents and cationic lipids. A first attempt towards this goal was made by Blessing et al. (1998), via an induced dimerization of a cysteine-based detergent (guanidinocysteine $\mathrm{N}$-decylamide), into a cystine-lipid on the template DNA. The DNA molecule was first condensed by addition of the reduced cationic detergent; in a second step, the detergent was oxidized, hence converted into a double-chain amphiphile. The particles thus obtained are monodisperse and spherical, with a negative surface potential, and do not transfect cells. Poor gene delivery could arise from the short hydrophobic chains (10 carbon atoms) of the molecule which differ from classical cationic lipids. A new detergent with an hydrophobic chain of 14 carbon atoms, ornithinyl-cysteinyltetradecylamide $\left(\mathrm{C}_{14}-\mathrm{CO}\right)$, was therefore synthetized. The polar head was also modified by replacing the guanidinium moiety by ornithine (with two protonated amines) that binds stronger to DNA (Rémy et al., 1994). The increased lipophily brought about by adding four methylene groups should be compensated by a more polar headgroup and the critical micellar concentration should not decrease too much.

With this perspective in mind, the aim of the present work was to characterize, by the previously developed biophysical tools (Clamme et al., 2000), the structure of the complexes of DNA with $\mathrm{C}_{14}$ - $\mathrm{CO}$ in its oxidized (dimer) form and to study their interactions with model membrane systems. Since the initial step of the formation of this complex involves the interaction of DNA with the non-oxidized (monomer) form of $\mathrm{C}_{14}-\mathrm{CO}$, we performed the same study with complexes formed by DNA with reduced $\mathrm{C}_{14}$-CO monomer and compared these results with those previously reported for CTAB/DNA complexes (Clamme et al., 2000).

\section{Materials and methods}

\subsection{Materials}

Egg yolk phosphatidylcholine (EYPC) and egg yolk phosphatidyl-DL-glycerol (EYPG), were pur- 
chased from Sigma. pCMV-luc plasmid DNA was produced and purified as described (Boussif et al., 1995). The DNA concentration expressed as mol of bases was determined by optical density, using an extinction coefficient of $6600 \mathrm{M}^{-1} \mathrm{~cm}^{-1}$ at 260 nm. Ethidium bromide (EtBr), YOYO-1, 1,6diphenylhexatriene (DPH), 2-(3-(diphenylhexatrienyl)propanoyl)- 1 - hexadecanoyl-sn-glycero-3phosphocholine (DPHpPC) and rhodamine-phosphatidylethanolamine (Rh-PE) were obtained from molecular Probes. Ornithinyl-cysteinyl-tetradecylamide $\left(\mathrm{C}_{14}-\mathrm{CO}\right)$ was synthesized according to Dauty et al. (2001) and guanidinocysteine N-decylamide $\left(\mathrm{C}_{10}-\mathrm{C}^{\mathrm{G}+}\right)$ was a generous gift of Thomas Blessing (Strasbourg). Chemical structures are represented in Fig. 1. Both molecules were kept under argon at $-80^{\circ} \mathrm{C}$ in neat ethanol. Free thiol concentration was measured spectrophotometrically according to Riddles et al. (1979).

\subsection{Preparation of large unilamellar vesicles $(L U V)$}

Phospholipids and probe (DPHpPC) stock solutions in chloroform-methanol (9:1) were mixed at a molar ratio of 100:1 and dried under vacuum by rotary evaporation onto the wall of a round-
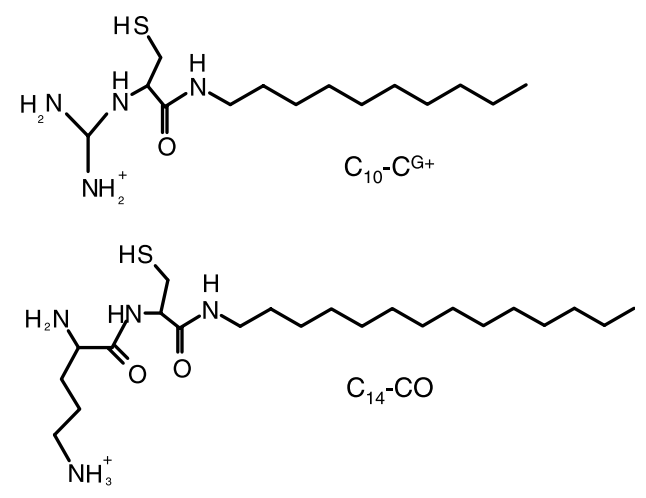

Fig. 1. Chemical structures of the oxidizable cationic surfactants used in this study. bottom flask. The lipid film was maintained under vacuum for at least $30 \mathrm{~min}$ to remove any residual solvent, and then hydrated with Hepes $15 \mathrm{mM}$, $\mathrm{pH} 7.4$ buffer for $30 \mathrm{~min}$. This preparation was followed by a vigorous vortex shaking for $2 \mathrm{~min}$ to obtain a solution of multilamellar vesicles (MLV). Large unilamellar vesicles (LUV) were then prepared by extrusion, at room temperature, of the MLV suspension through polycarbonate filters (Nucleopore), using a Lipex Biomembranes extruder. The size of the filter was first $0.2 \mu \mathrm{m}$ (seven passages) and thereafter $0.1 \mu \mathrm{m}$ (10 passages). A homogeneous population of vesicles was obtained ( $0.11-0.12 \mu \mathrm{m}$ diameter), as checked by quasi-elastic light scattering measurements with a N4SD Coultronics Nanosizer.

\subsection{Preparation of giant unilamellar vesicles $(G U V)$}

Giant unilamellar vesicles made from EYPC were prepared according to Moscho et al. (1996). Briefly, the lipids were dissolved in chloroform $(0.1 \mathrm{M})$, and $850 \mu \mathrm{l}$ of this solution was added to $150 \mu \mathrm{l}$ of methanol. The aqueous phase $(7 \mathrm{ml}$ of Hepes $15 \mathrm{mM}$, pH 7.4 buffer) was then carefully added along the flask walls. Two phases were obtained and the organic solvent was evaporated in a rotary evaporator (Buchi rotavapor ' $R$ ') at $40^{\circ} \mathrm{C}$ and $40 \mathrm{rpm}$ for $5 \mathrm{~min}$. For fluorescent-labelled liposomes, 1:2000 of Rh-PE was added to lipids.

\subsection{Formation of DNA-surfactant complexes}

The complexes were prepared in Hepes $15 \mathrm{mM}$, pH 7.4 buffer by mixing pCMV-luc plasmid DNA at a final concentration of $10 \mu \mathrm{M}$ phosphate with an appropriate amount of detergent to reach a given \pm charge ratio, $r$, assuming that the two positive charges of a single $\mathrm{C}_{14}$-CO molecule neutralise two DNA phosphate groups. The mixture was kept at room temperature for $4 \mathrm{~h}$ to allow for complete $\mathrm{C}_{14}-\mathrm{CO}$ oxidation. The studies with the $\mathrm{C}_{14}$ - $\mathrm{CO}$ monomer form were performed in the same buffer, but previously degassed and containing $10 \mathrm{mM}$ dithiothreitol to avoid detergent oxidation. 


\subsection{Fluorescence steady-state measurements}

Steady-state fluorescence measurements were performed on a thermostated SLM 48000 spectrofluorimeter. The binding of $\mathrm{C}_{14}-\mathrm{CO}$ to DNA was examined using the fluorescence signal of ethidium bromide $(\mathrm{EtBr})$. This intercalating agent was added at a 1:50 molar ratio to a $10 \mu \mathrm{M}$ DNA concentration in Hepes $15 \mathrm{mM}$, pH 7.4. $\mathrm{C}_{14}-\mathrm{CO}$ was then added to the EtBr-DNA complexes up to $r=3.5$; each ratio being prepared as a separate solution. The excitation wavelength for EtBr was $510 \mathrm{~nm}$.

The interaction of YOYO-labelled $\mathrm{C}_{14}-\mathrm{CO} /$ DNA complexes with DPHpPC-labelled vesicles was characterized by fluorescence resonance energy transfer (FRET) between DPHpPC (donor) and YOYO-1 (acceptor). The transfer efficiency was calculated by:

$E=1-\frac{F_{\mathrm{DA}}}{F_{\mathrm{D}}}$

where $F_{\mathrm{D}}$ and $F_{\mathrm{DA}}$ correspond to the fluorescence intensity of the donor, in the absence and in the presence of the acceptor, respectively. The intensities were corrected from screening effects at both excitation and emission wavelengths according to Pigault and Gérard (1984). The Förster critical distance $R_{0}$ between the two fluorophores was calculated previously and found equal to $47 \AA$ (Clamme et al., 2000). Finally, once the transfer efficiency $E_{\mathrm{D}}$ determined, the average distance, $R$, between the acceptor and the donor was calculated using:

$R=R_{0}\left(\frac{1}{E_{D}}-1\right)^{1 / 6}$

A SLM 8000 spectrofluorimeter, in its T-format configuration, was used to measure steady-state fluorescence anisotropy. The DPH excitation wavelength was $360 \mathrm{~nm}$ and the emitted light was monitored through $435 \mathrm{~nm}$ interference filters (Schott). A home built device ensured the automatic rotation of the excitation polarizer, allowing continuous measurement of the anisotropy.

\subsection{Fluorescence lifetime measurements}

DPH fluorescence lifetimes were measured by the phase and modulation method using a SLM 48000 spectrofluorimeter in its lifetime configuration. The excitation was set at $360 \mathrm{~nm}$, and the whole fluorescence spectrum was taken through high pass filters (Schott, KV408). The modulation frequencies of the exciting light ranged from 5 to $90 \mathrm{MHz}$. DPH in heptane was used as a lifetime reference, with a single exponential decay of 6.75 ns (Barrow and Lentz, 1983). Data analysis was performed using the SLM software. As frequently observed with DPH embedded in such systems, a double-exponential decay was obtained, from which we calculated the average fluorescence lifetime by $<\tau>=\Sigma \alpha_{\mathrm{i}} \tau_{\mathrm{i}}$, where $\tau_{\mathrm{i}}$ and $\alpha_{\mathrm{i}}$ are the lifetimes and their associated amplitudes, respectively.

$\mathrm{EtBr}$ fluorescence lifetimes were measured by the single-photon counting method using a pulsepicked frequency doubled Ti-sapphire laser pumped by a Millenium X diode laser (SpectraPhysics) as previously described (Clamme et al., 2000). The excitation and emission wavelengths were 443 and $620 \mathrm{~nm}$, respectively.

\subsection{Confocal microscopy}

Complexes of pCMV-luc plasmid DNA with $\mathrm{C}_{14}$-CO in $15 \mathrm{mM}$ Hepes pH 7.4 buffer, at $10 \mu \mathrm{M}$ DNA with a 1:1 charge ratio were used in confocal microscopy experiments. The complexes were transferred into chambered coverglass (Lab-Tek). The complexes were labelled with $0.2 \mu \mathrm{M}$ YOYO-1 and the GUVs with Rh-PE. The solutions were directly observed with an MRC-1024 ES (Bio-Rad) confocal laser scanning imaging system equipped with an inverted microscope and an $\times 60$ water immersion objective (Nikon).

\section{Results}

\subsection{Characterization of $C_{14}-\mathrm{CO} / \mathrm{DNA}$ complexes}

\subsubsection{Condensation of DNA}

Condensation of DNA occurs spontaneously when the DNA phosphate charges are neutralized by $90 \%$ (Bloomfield, 1996). This is notably the case during the formation of complexes with polycationic molecules, as for example polylysine or 


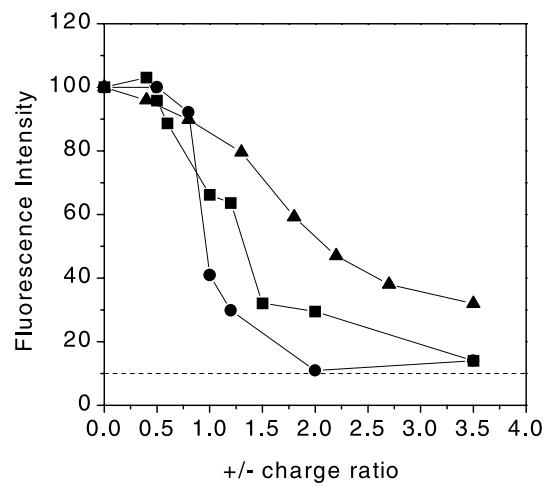

Fig. 2. Plasmid DNA condensation induced by the addition of cationic surfactants. The condensation is followed by measuring the fluorescence intensity of the DNA intercalating probe EtBr added at a 1:50 molar ratio of probe to nucleotide. ( $\Delta$ ) CTAB; $(\bullet) \mathrm{C}_{14}$-CO monomer; $(\boldsymbol{\square}) \mathrm{C}_{14}$-CO dimer. The dotted line corresponds to the fluorescence intensity of free EtBr. See text for experimental conditions.

cationic liposomes (Toncheva et al., 1998; Mel'nikova et al., 1999). Furthermore, condensation renders DNA inaccessible to the intercalating fluorophore ethidium bromide (EtBr), causing a decrease in its fluorescence signal (Gershon et al., 1993; Eastman et al., 1997; Toncheva et al., 1998). Accordingly, we first investigated the accessibility of the complexed DNA to EtBr. In presence of $\mathrm{C}_{14}-\mathrm{CO}$, either in its monomer or dimer form, the $\mathrm{EtBr}$ fluorescence does not change significantly at low $r$ (Fig. 2). In contrast, a steep decrease of fluorescence intensity is observed, for both forms, at $r$ close to 1 and this intensity reaches, at $r$ between 2 and 3, the level of EtBr in the absence of DNA. In order to check if this sharp fluorescence decrease could be attributed to an ejection of $\mathrm{EtBr}$ from its intercalation site and not to some environmental changes or quenching processes, we performed a time-resolved fluorescence investigation. According to Le Pecq and Paoletti (1967), free and DNA-bound EtBr are characterized by fluorescence lifetimes of 1.6-1.8 and $22-23 \mathrm{~ns}$, respectively. In our conditions, the amplitude of the short lifetime is about $35 \%$ for the plasmid DNA in the absence of $\mathrm{C}_{14}$-CO. Incremental addition of $\mathrm{C}_{14}-\mathrm{CO}$ does not affect the fluorescence lifetimes of bound and free species but strongly reduces the relative amplitude of the long lifetime in favour of the short one. As an example, for the dimer form, the amplitude of the short component increases to 57 and $69 \%$ at $r=1$ and 1.5 , respectively. This indicates that EtBr is displaced upon binding of $\mathrm{C}_{14}-\mathrm{CO}$, in keeping with a condensation of the DNA. The EtBr ejection curves with both forms of $\mathrm{C}_{14}-\mathrm{CO}$ are highly similar and shifted to low $r$ as compared to CTAB (Fig. 2). As EtBr ejection strongly depends on the affinity of the detergent for DNA (Mel'nikov et al., 1995b), it appears that both $\mathrm{C}_{14}$-CO forms have higher affinities for DNA than CTAB.

\subsubsection{Physicochemical properties of the} micelle-like domains of $C_{14}-C O / D N A$ complexes

Upon addition of increasing amounts of $\mathrm{C}_{14^{-}}$ $\mathrm{CO}$ to plasmid DNA, the formation of hydrophobic $\mathrm{C}_{14}-\mathrm{CO}$ domains along the DNA was followed by the increase in fluorescence intensity of DPH. This probe is non-fluorescent in water but presents a high quantum yield in apolar medium and thus is commonly used to characterize the hydrophobic core of lipid vesicles or biomembranes (Lentz, 1989). In the absence of $\mathrm{C}_{14}-\mathrm{CO}$, a weak and smooth DPH fluorescence spectrum is observed (Fig. 3), indicating that DNA itself could capture and protect some DPH from surrounding water. Addition of increasing amounts of $\mathrm{C}_{14}-\mathrm{CO}$, either in its monomer or dimer form, induces a strong fluorescence intensity increase, confirming the rapid formation of the hydrophobic domains and an increase in their size and number with $r$. The fluorescence intensities obtained with both $\mathrm{C}_{14}$-CO forms are not very different (Fig. 3) but, in contrast to CTAB (Clamme et al., 2000), a plateau of fluorescence with increasing $r$ is not observed. This may probably be related to the aggregation phenomenon that appears at high $r$.

The structuration of the hydrophobic domains was further characterized by the mobility of DPH as estimated by the rotational correlation time, $\rho$. The parameter, $\rho$, is related to the average fluorescence lifetime, $\langle\tau\rangle$, the DPH fundamental anisotropy, $a_{0}=0.362$ (Shinitzky and Barenholz, 


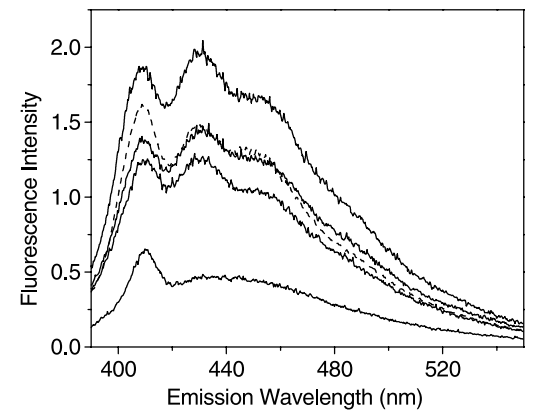

Fig. 3. Formation of hydrophobic micelle-like domains in dimeric $\mathrm{C}_{14}-\mathrm{CO} / \mathrm{DNA}$ complexes. This formation is followed through the fluorescence of $0.2 \mu \mathrm{M}$ DPH. The complexes are formed with $10 \mu \mathrm{M}$ plasmid DNA and $\mathrm{C}_{14}-\mathrm{CO}$ added to a \pm charge ratio $r$ of $0,0.6,1,1.4$ from bottom to top, respectively. For comparison, the dotted curve corresponds to a monomeric $\mathrm{C}_{14}-\mathrm{CO} / \mathrm{DNA}$ complex at $r=1.4$. The excitation wavelength is $360 \mathrm{~nm}$.

1978), and the steady-state fluorescence anisotropy, $a$, by Perrin-Weber's equation:

$\left(\frac{a_{0}}{a}-1\right)=3 \frac{\tau}{\rho}$

The fluorescence parameters of DPH embedded in different surfactant/DNA complexes are summarized in Table 1. We have considered not only the data obtained with both forms of $\mathrm{C}_{14}-\mathrm{CO}$, but also, for comparison, those obtained with CTAB (Clamme et al., 2000) and the oxidized form of guanidinocysteine $\quad \mathrm{N}$-decylamide $\left(\mathrm{C}_{10}-\mathrm{C}^{\mathrm{G}+}\right)$ (Blessing et al., 1998). The rotational correlation times $\rho$ appear to be essentially governed by the value of the steady-state fluorescence anisotropy, since the mean fluorescence lifetimes $\langle\tau\rangle$ are similar for the different complexes. The rotational correlation times $\rho$ are relatively large for $\mathrm{C}_{14}-\mathrm{CO}$ complexes. With the monomer form of $\mathrm{C}_{14}-\mathrm{CO}$, the value $(\rho=12 \mathrm{~ns})$ approaches the value obtained with egg yolk phosphatidylcholine vesicles ( $\rho=14.5 \mathrm{~ns}$ ), while with the dimer form it is even higher $(\rho=20 \mathrm{~ns})$. In contrast, the $\rho$ values for the complexes obtained with either CTAB or oxidized $\mathrm{C}_{10}-\mathrm{C}^{\mathrm{G}+}$ are lower ( $\left.\sim 10 \mathrm{~ns}\right)$. Accordingly, both the nature of the detergent and its form (monomer or dimer) are of critical importance in the structuration of the surfactant/DNA complexes.

\subsection{Interactions of $C_{14}-C O / D N A$ complexes with $L U V$}

In a previous study, the inability of CTAB/ DNA complexes to efficiently transfect cells has been shown to be related to their interactions with the plasma membrane (Clamme et al., 2000).

Table 1

Fluorescence parameters of DPH in cationic surfactant/DNA complexes ${ }^{\mathrm{a}}$

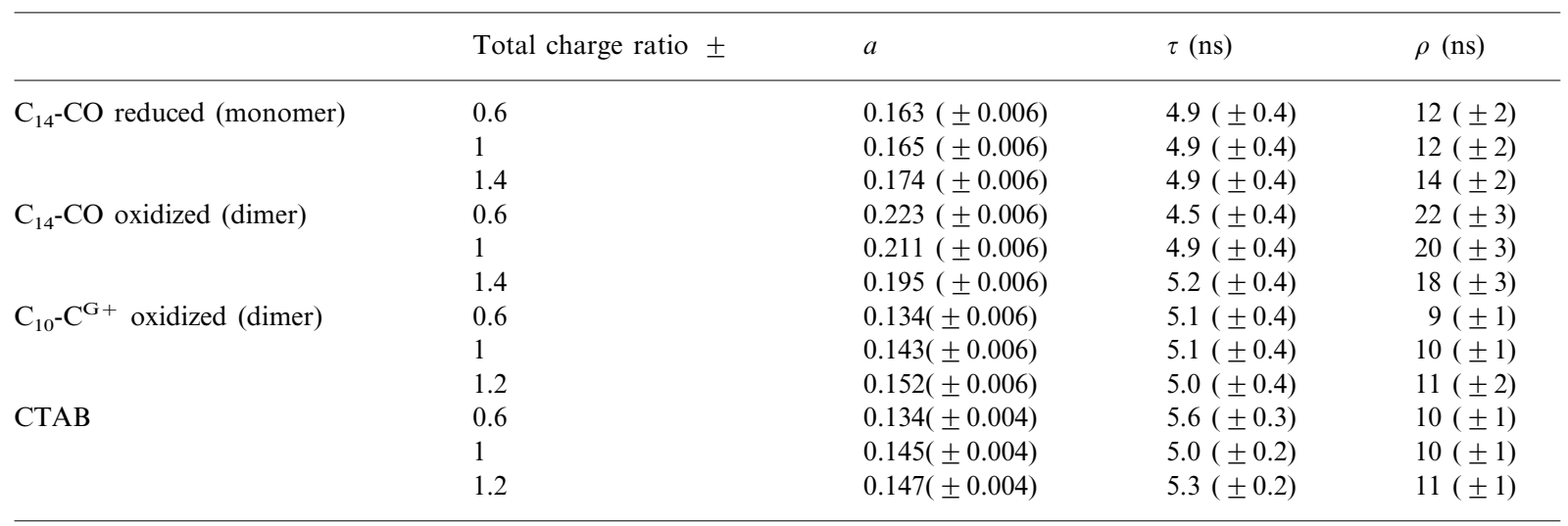

\footnotetext{
${ }^{a}$ pCMV-LUC plasmid DNA and DPH concentrations are 10 and $0.2 \mu \mathrm{M}$, respectively (50 and $0.5 \mu \mathrm{M}$ in the case of CTAB). Excitation and emission wavelengths are 360 and $435 \mathrm{~nm}$, respectively. The steady-state anisotropy $a$, the average fluorescence lifetime $\langle\tau\rangle$, and the rotational correlation time $\rho$ are expressed as the mean for 3 experiments.
} 
Moreover, it has been evidenced that this limiting step could be adequately modelled by the interaction of the complexes with neutral vesicles. In this respect, the interactions of $\mathrm{C}_{14}-\mathrm{CO} / \mathrm{DNA}$ complexes with lipid bilayers were investigated in the same way by using LUV composed either of EYPC, which is a dipolar zwitterion with no net charge, or of an equimolar mixture of EYPC and EYPG. The presence of EYPG renders the vesicle anionic and may thus constitute a model for plasma membrane cytoplasmic leaflets (Devaux, 1991). Both egg yolk lipids are presenting a liquid crystalline phase at room temperature.

To evidence these interactions, we first measured, by FRET, the average distance between an acceptor probe linked to $\mathrm{C}_{14}-\mathrm{CO} / \mathrm{DNA}$ complexes and a donor probe covalently linked to a phospholipid, thus being an integral part of the membrane bilayer. The acceptor is YOYO-1, which is a bis-intercalating agent characterized by a very high affinity for DNA (Hirons et al., 1994). The fluorescence intensity of free YOYO-1 is 3200 times lower than that of the bound form and could thus be neglected. Up to $r=1$, the fluorescence of bound YOYO-1 is only slightly quenched by $\mathrm{C}_{14}$-CO (less than $20 \%$ of quenching; data not shown) and, as previously shown with CTAB (Clamme et al., 2000), lifetime measurements suggest that the quenching is not due to the ejection of the probe from its intercalation site, but to a modification of its environment. Consequently, YOYO-1 fluorescence is always localized on the DNA molecule. The labelled phospholipid used as a donor is DPHpPC. The fluorescence spectra of $\mathrm{C}_{14}-\mathrm{CO} / \mathrm{DNA}$ complexes in the presence of neutral vesicles (EYPC) are shown in Fig. 4. For the complexes with monomeric $\mathrm{C}_{14}-\mathrm{CO}$, we observe an important fluorescence energy transfer as shown by the decrease of donor fluorescence and the appearance of acceptor fluorescence. At $r$ greater than 1, this general trend is maintained, but the lower quantum yield of quenched YOYO1 and the turbidity of the solutions due to aggregation affect to some extent the fluorescence signal, as shown by the disappearance of the iso-emissive point. In sharp contrast to $\mathrm{C}_{14}-\mathrm{CO}$ monomers, there is no evidence of energy transfer by using complexes with $\mathrm{C}_{14}$-CO dimers. A similar
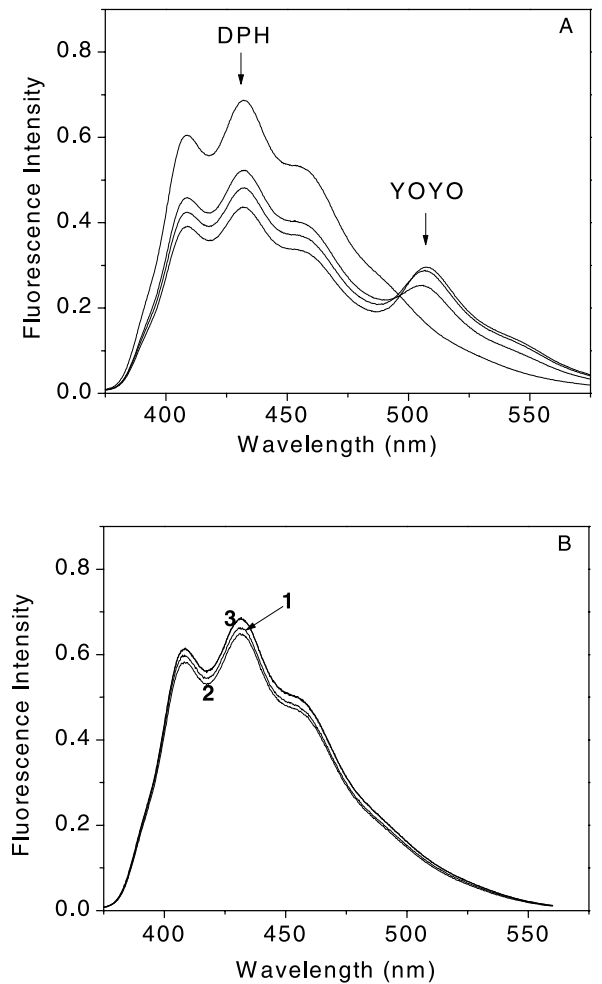

Fig. 4. Fluorescence spectra of DPHpPC-labelled EYPC vesicles in the presence of YOYO-labelled $\mathrm{C}_{14}-\mathrm{CO} / \mathrm{DNA}$ complexes. The complexes are obtained with $10 \mu \mathrm{M}$ DNA and either $\mathrm{C}_{14}-\mathrm{CO}$ monomer form (A) or $\mathrm{C}_{14}$-CO dimer form (B) added in appropriate amounts to obtain: $r=0$ (1); $r=1$ (2); $r=0.8(3) ; r=0.6$ (4). Curves 3 and 4 are superimposed in panel B. The excitation wavelength is $360 \mathrm{~nm}$.

absence of energy transfer is noted when both types of complexes (monomer or dimer) are in the presence of anionic vesicles made of an equimolar EYPC/EYPG mixture (spectra not shown). Obviously, a close contact between YOYO-labelled DNA and DPHpPC-labelled vesicles only occurs in the case of monomeric $\mathrm{C}_{14}-\mathrm{CO} / \mathrm{DNA}$ complexes in the presence of neutral EYPC vesicles, with an average distance $R$ between the two labels varying from 62 to $65 \AA(0.6 \leqslant r \leqslant 1)$ as calculated from $R_{0}$ and the transfer efficiency $E_{\mathrm{D}}$ obtained from the quenching of the donor.

The stable binding of monomeric $\mathrm{C}_{14}-\mathrm{CO} / \mathrm{DNA}$ complexes with the membrane bilayers of EYPC vesicles was confirmed by confocal microscopy on GUV. As shown in Fig. 5, the fluorescence of 
YOYO-labelled DNA (YOYO-1 being directly excited at $488 \mathrm{~nm}$, and not by an energy transfer process) appears clearly all around the surface of the giant vesicles and suggests a sticking of DNA along the bilayer of the giant vesicle. In contrast, no sticking of DNA to the vesicles is seen with dimeric $\mathrm{C}_{14}-\mathrm{CO} / \mathrm{DNA}$ complexes, which are only visible as small fluorescent spots spread all over the solution (not shown).

To get additional information, EtBr intercalation was used to investigate the condensation state of DNA in $\mathrm{C}_{14}-\mathrm{CO} / \mathrm{DNA}$ complexes in the presence of phospholipid vesicles. With monomeric $\mathrm{C}_{14}-\mathrm{CO} / \mathrm{DNA}$ complexes, the addition of either neutral or anionic vesicles leads to an almost complete recovery of $\mathrm{EtBr}$ fluorescence (Fig. 6A). This suggests that the interaction with the vesicles induces a re-exposure of $\mathrm{EtBr}$ intercalation sites that may be consecutive to DNA decondensation. In sharp contrast, the addition of both types of vesicles to dimeric $\mathrm{C}_{14}-\mathrm{CO} / \mathrm{DNA}$ complexes is unable to induce recovery of $\mathrm{EtBr}$ fluorescence (Fig. 6B), suggesting that DNA remains condensed.

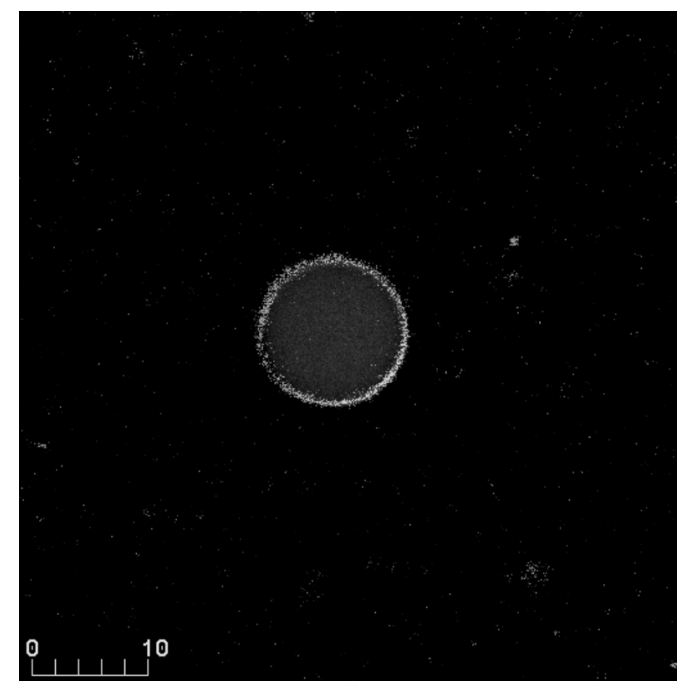

Fig. 5. Confocal picture of an EYPC giant vesicle in the presence of YOYO-labelled monomeric $\mathrm{C}_{14}-\mathrm{CO} / \mathrm{DNA}$ complexes, at $r=1$. The complexes, bound at the surface of the vesicle, appear green and the rhodamine-labelled vesicle red. This image is recombined from YOYO- $1\left(\lambda_{\text {exc }}=488 \mathrm{~nm}\right.$; $\left.\lambda_{\mathrm{em}}=522 \mathrm{~nm}\right)$ and rhodamine $\left(\lambda_{\mathrm{exc}}=568 \mathrm{~nm} ; \lambda_{\mathrm{em}}=585 \mathrm{~nm}\right)$ fluorescence signals. The scale bar corresponds to $10 \mu \mathrm{m}$.
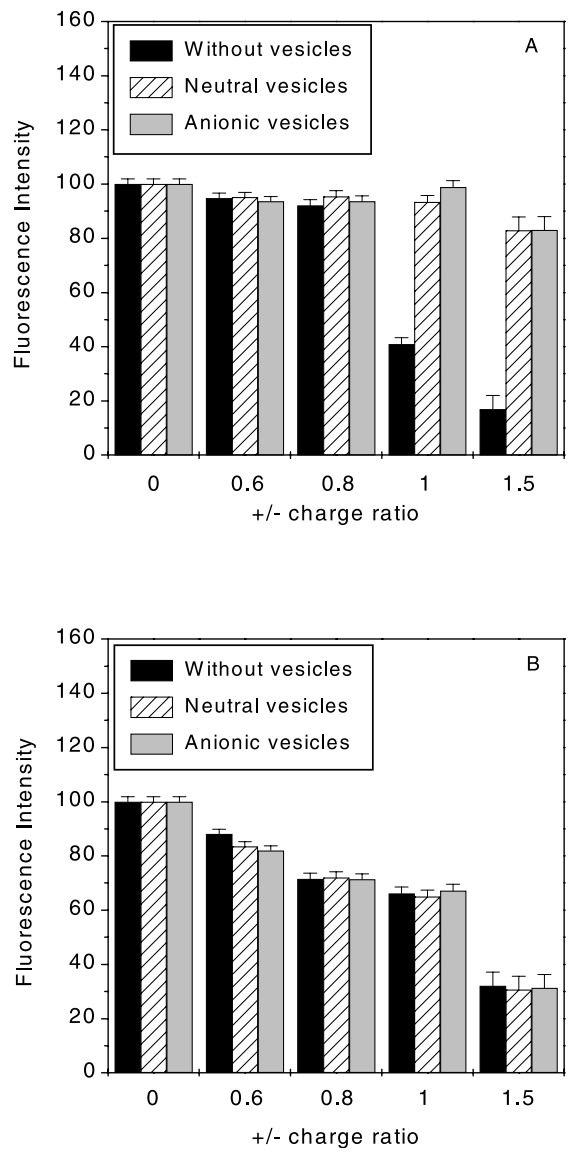

Fig. 6. EtBr intercalation, as followed by its fluorescence intensity, for $\mathrm{C}_{14}-\mathrm{CO} / \mathrm{DNA}$ complexes in the presence of neutral or anionic vesicles. The complexes are formed as in Fig. 4 with either $\mathrm{C}_{14}-\mathrm{CO}$ monomer form (A) or $\mathrm{C}_{14}$ - $\mathrm{CO}$ dimer form (B).

\section{Discussion}

In this report, we investigated the interaction of plasmid DNA with a new cationic cystine-based surfactant: ornithinyl-cysteinyl-tetradecylamide. By analogy to guanidino-cysteine $\mathrm{N}$-decylamide (Blessing et al., 1998), this detergent is able to adopt a lipid-like structure via spontaneous oxidative dimerization. As cationic detergents were shown to condense DNA into discrete particles consisting of a single nucleic acid molecule (Mel'nikov et al., 1995a,b), such a dimerization is supposed to 'freeze' the particles and lead to a better transfection efficiency. As these molecules 
were conceived with the aim to define a new class of transfection non-viral vectors, it is of importance to further characterize the structural and physicochemical aspects of this oxidizable detergent in complexes with DNA.

Since both monomer and dimer forms of $\mathrm{C}_{14^{-}}$ $\mathrm{CO}$ are able to efficiently expel ethidium bromide from its DNA binding sites, it can be readily inferred that both forms of $\mathrm{C}_{14}-\mathrm{CO}$ are able to condense plasmid DNA. Comparison with CTAB reveals that both $\mathrm{C}_{14}$-CO forms induce a more efficient compaction of DNA than CTAB. For instance, only $60 \%$ of $\mathrm{EtBr}$ is expelled from CTAB/DNA complexes at $r=2$, while a complete expulsion of $\mathrm{EtBr}$ is obtained with $\mathrm{C}_{14}-\mathrm{CO} / \mathrm{DNA}$ complexes at the same $r$. As the displacement curves of EtBr have been shown to parallel the corresponding binding isotherms (Mel'nikov et al., 1995b), we infer from these data that the binding affinities of $\mathrm{C}_{14}-\mathrm{CO}$ are higher than those of CTAB. In fact, the total expulsion of EtBr for $r \geqslant 2$ strongly suggests that $\mathrm{C}_{14}-\mathrm{CO}$ binding is almost stoichiometric in our conditions, hence our inability to discriminate between the binding constants of each $\mathrm{C}_{14}-\mathrm{CO}$ forms for DNA. The higher affinities of $\mathrm{C}_{14}-\mathrm{CO}$ versus CTAB could likely be due to the simultaneous binding of the two positive charges of the $\mathrm{C}_{14}-\mathrm{CO}$ ornithine moiety to two DNA phosphate groups, whereas the single CTAB positive charge interacts with only one phosphate group. Moreover, it was shown that polyamines may easily adapt to the stereochemical requirements of polyphosphates (MernissiArifi et al., 1996), whereas the head size of the ionic head group of CTAB is larger $(\sim 6.9 \AA)$ than the charge-charge distance in DNA $(\sim 5 \AA)$ (Blessing et al., 1998). Thus, steric hindrance could limit the degree of binding of the trimethylammonium groups to the DNA phosphates, where a closer approach of the protonated amine groups of the ornithine moiety could favour it.

The formation of hydrophobic domains along the DNA chain was followed by the increase of DPH fluorescence intensity, as shown in Fig. 3. These domains already appear at sub-stoichiometric ratios $(r<1)$, suggesting a typical cooperative phenomenon for binding of the monomer or dimer surfactant, in full keeping with the model of discrete coil-globule transition (Mel'nikov et al., 1995a,b). These hydrophobic (micelle-like) domains were further characterized by the mobility of DPH, as estimated by the rotational correlation time $\rho$ (Table 1). This parameter, which is related to the rotational diffusion coefficient by $\rho=\left(2 \mathrm{D}_{\mathrm{r}}\right)^{-1}$, can be used to estimate the molecular order of the probe environment. The molecular order for the hydrophobic domains of monomeric $\mathrm{C}_{14}-\mathrm{CO} / \mathrm{DNA}$ complexes is relatively high $(\rho \sim 12$ ns) since it approaches that of the lipidic core in liquid crystal EYPC vesicles $(\rho \sim$ $14.5 \mathrm{~ns})$. It is also larger than that in CTAB/DNA complexes $(\rho \sim 10 \mathrm{~ns})$, in spite of the longer hydrophobic chain of CTAB (16 atoms instead of 14). This difference could probably be explained by the above-mentioned steric reasons, with as a consequence a better packing of the hydrophobic chains of $\mathrm{C}_{14}-\mathrm{CO}$ as compared to CTAB. When $\mathrm{C}_{14}-\mathrm{CO}$ is oxidized on the template DNA and thus transformed into a lipid-like molecule, $\rho$ reaches a notably higher value $(\sim 20 \mathrm{~ns})$, a result which may be the consequence of further structured and stabilized micelle-like domains induced by the formation of the disulfide bridges. The influence of such a structuration induced by the dimerization of the detergent is confirmed by considering the results obtained with oxidized $\mathrm{C}_{10^{-}}$ $\mathrm{C}^{\mathrm{G}+} /$ DNA complexes. In this case, a complex made with the dimeric form of a surfactant with only 10 carbon atoms shows a similar molecular order $(\rho \sim 10 \mathrm{~ns})$ than that of complexes with a single chain surfactant (CTAB) with 16 carbon atoms.

Considering the $\mathrm{C}_{14}-\mathrm{CO} / \mathrm{DNA}$ complexes as potential non-viral vectors for gene delivery, the cell plasma membrane will be the first barrier to cross. Thus, studying the behaviour of the complexes in the presence of lipid vesicles should highlight on their possible passive interactions (without any active biological process) with a membrane bilayer. Two types of vesicles were considered: neutral vesicles (100\% EYPC) and anionic vesicles (50\% EYPC, 50\% EYPG). Taking into account the more common composition of each leaflet of a plasma membrane, a neutral vesicle could be considered to mimic the external leaflet (rich in PC and PE) and an anionic vesicle 
the cytoplasmic leaflet (rich in anionic lipids like PS and PG) (Devaux, 1991). Fluorescence resonance energy transfer between the fluorescent moiety of labelled phospholipids, (DPHpPC, donors) and YOYO-1 molecules (acceptors) jointly bound to the DNA in the complexes only occurs for monomeric $\mathrm{C}_{14}-\mathrm{CO} / \mathrm{DNA}$ complexes in the presence of neutral EYPC vesicles. The average inter-fluorophore distance is found to be around $63 \AA, r$ varying from 0.6 to 1 . The proximity between the two probes clearly suggests a stable binding between the complex and the vesicle. Binding is confirmed by confocal microscopy showing sticking of DNA onto the surface of a neutral GUV (Fig. 5). In all other cases (anionic vesicles and/or dimeric $\mathrm{C}_{14}-\mathrm{CO}$ ), no energy transfer appears, pointing out the absence of any stable binding of the complexes to the vesicles.
Furthermore, comparison of the DNA condensation state, obtained through EtBr intercalation, for the different complexes in the presence of both types of vesicles allows us to further characterize these interactions and to propose the scheme depicted in Fig. 7. In the case of monomeric $\mathrm{C}_{14^{-}}$ $\mathrm{CO} / \mathrm{DNA}$ complexes, the interaction with either neutral or anionic vesicles leads to a quasi complete recovery of $\mathrm{EtBr}$ fluorescence (Fig. 6A), indicating that the interaction induces a decondensation of DNA. When combined with FRET data, this suggests that the unfolded DNA remains bound to the neutral vesicles, but not to the anionic vesicles. This behaviour is similar to the one we showed for CTAB/DNA complexes (Clamme et al., 2000). Surfactant single-chain molecules (monomeric $\mathrm{C}_{14}$-CO) may be incorporated into the phospholipid bilayer due to their partition equilibrium between lipid and aqueous
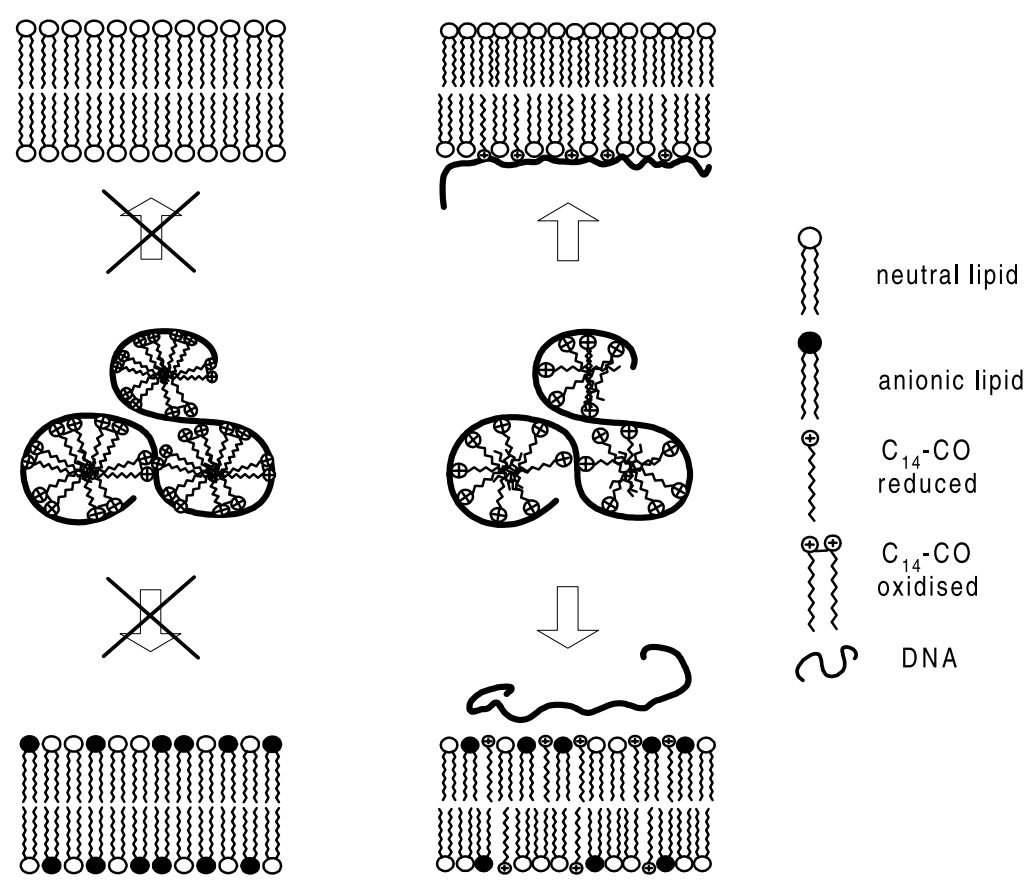

Fig. 7. Proposed mechanism for the interaction of $\mathrm{C}_{14}-\mathrm{CO} / \mathrm{DNA}$ complexes with vesicles. Left: the dimeric (oxidized) $\mathrm{C}_{14}-\mathrm{CO} / \mathrm{DNA}$ complexes do not interact and remain condensed either with neutral vesicles (top) or anionic vesicles (bottom); Right: the interaction of monomeric (reduced) $\mathrm{C}_{14}-\mathrm{CO} / \mathrm{DNA}$ complexes with neutral vesicles (top) induces an opening of the micelle-like domains and an insertion of $\mathrm{C}_{14}-\mathrm{CO}$ molecules in the external layer. After the insertion, the detergent molecules are still able to bind the unfolded DNA. In the presence of anionic vesicles (bottom), the $\mathrm{C}_{14}-\mathrm{CO}$ molecules are also inserted into the lipid bilayer, but are now forming neutral ion pairs with anionic lipids. Since no positive charges are then available, the unfolded DNA is released into the bulk solution. 
phases, resulting in the opening of the micelle-like domains of the complexes. With neutral vesicles, the $\mathrm{C}_{14}$-CO molecules may be spread all over the external leaflet and available to interact, via electrostatic interactions, with the unfolded DNA. As a consequence, the DNA molecules bind to the vesicle surface in an extended configuration. With anionic vesicles, the PG lipids (in excess) probably form neutral ion pairs with $\mathrm{C}_{14}-\mathrm{CO}$ molecules. Since no positive charges remain available, the unfolded DNA molecules are released into the bulk solution.

In sharp contrast, the addition of vesicles to the dimeric $\mathrm{C}_{14}-\mathrm{CO} / \mathrm{DNA}$ complexes does not lead to DNA decondensation (Fig. 6B). Combined with the absence of energy transfer, this strongly suggests that there is no disassembly of the complexes induced by the presence of either neutral or anionic vesicles. As we are in the presence of a lipid-like surfactant forming a condensed globule with DNA, such a behaviour may be easily explained. Indeed, lipid molecules with long saturated hydrocarbon chains have a very low solubility in water (Roseman and Thompson, 1980) so that their escape from a complex into the bulk solution may be considered as highly unlikely. Thus, the lipid-like $\mathrm{C}_{14}-\mathrm{CO}$ dimers are unable to diffuse in the buffer and to partition into the phospholipid vesicles, whatever the charge of the vesicles. This leaves the complexes preserved as a whole, without any interaction with the vesicles.

\section{Conclusion}

This work allowed us to characterize the formation of complexes between plasmid DNA and a new cationic surfactant, ornithinyl-cysteinyl-tetradecylamide $\left(\mathrm{C}_{14}-\mathrm{CO}\right)$, either reduced (detergent monomer) or oxidized (lipid-like dimer), and to study the behaviour of these complexes in the presence of model membrane vesicles.

Concerning the monomeric $\mathrm{C}_{14}-\mathrm{CO}$, the structure of the complexes as well as their interactions with phospholipid vesicles were found similar to those observed with the model detergent CTAB. Neither replacing the trimethyl-ammonium group by ornithine, nor the slight shortening of the hydrophobic chain have a significant influence on the physicochemical properties of the complexes. More original and challenging in the perspective of non-viral transfection is the high stability of oxidized $\mathrm{C}_{14}-\mathrm{CO} / \mathrm{DNA}$ complexes. The aim of the synthesis of such oxidizable detergents was to freeze the particle obtained after monomolecular condensation of the DNA. An increased stability of the particles was clearly evidenced by the increase of the molecular order of the micelle-like domains and the inability of these domains to be opened in the presence of lipid vesicles. This constitutes obviously a favourable feature for enabling the complex to be internalized into cells without any retention of the DNA on the plasma membrane. However, the absence of any interaction of the complexes with either neutral or negatively charged vesicles suggests that the necessary initial interaction with the plasma membrane is not occurring. This may be linked to the negative surface charge of the complexes, as assessed by zeta potential measurements (data not shown), which does not favour the binding to the neutral or negatively charged residues of membranes. A possible solution to this dilemma could be to graft on the detergent (or on a molecule able to insert into the micelle-like domains) some ligand able to bind the complexes to a receptor present on the cell membrane. Moreover, the high stability of the complexes may also have unfavourable consequences on later steps. Indeed, if we assume that the complexes are internalized into cells by endocytosis, DNA release is a necessary event for transcription to occur (Xu and Szoka, 1996; Zelphati and Szoka, 1996). Release may occur after destabilization of the endosomal membranes, followed by flip-flop of anionic lipids from the cytoplasmic-facing monolayer and the formation of neutral ion pairs with the cationic lipids (Bhattacharya and Mandal, 1998). Due to the high stability of the dimeric $\mathrm{C}_{14}-\mathrm{CO} / \mathrm{DNA}$ complexes, this step is unlikely to occur and completion of the transfection process, up to the entry of the DNA into the nucleus, will be hindered. This may further explain the low transfection efficiency of such complexes at the $( \pm)$ ratios used in the present study. 


\section{Acknowledgements}

We thank Dr. J.-S. Remy for helpful discussion and J.-P. Clamme for his skilful assistance. This work was supported by the Association pour la Recherche sur le Cancer (ARC), the Ligue Régionale du Bas-Rhin et du Haut-Rhin contre le Cancer, and the Fondation pour la Recherche Médicale. D.L. and E.D. are recipient of doctoral fellowships from the Ministère de la Recherche and the Association Française de Lutte contre la Mucoviscidose (AFLM), respectively.

\section{References}

Barrow, D.A., Lentz, B.R., 1983. The use of isochronal reference standards in phase and modulation fluorescence lifetime measurements. J. Biochem. Biophys. Methods 7, 217-234.

Bhattacharya, S., Mandal, S.S., 1998. Evidence of interlipidic ion-pairing in anion-induced DNA release from cationic amphiphile-DNA complexes. Mechanistic implications in transfection. Biochemistry 37, 7764-7777.

Blessing, T., Rémy, J.-S., Behr, J.-P., 1998. Monomolecular collapse of plasmid DNA into stable virus-like particles. Proc. Natl. Acad. Sci. USA 95, 1427-1431.

Bloomfield, V.A., 1996. DNA condensation. Curr. Opinion Struct. Biol. 6, 334-341.

Boussif, O., Lezoual'ch, F., Zanta, M.A., Mergny, M.D., Scherman, D., Demeneix, B., Behr, J.-P., 1995. A versatile vector for gene and oligonucleotide transfer into cells in culture and in vivo: polyethylenimine. Proc. Natl. Acad. Sci. USA 92, 7297-7301.

Clamme, J.-P., Bernacchi, S., Vuilleumier, C., Duportail, G., Mély, Y., 2000. Gene transfer by cationic surfactants is essentially limited by the trapping of the surfactant/DNA complexes onto the cell membrane: a fluorescence investigation. Biochim. Biophys. Acta 1467, 347-361.

Dauty, E., Remy, J.-S., Blessing, T., Behr, J.-P., 2001. Dimerizable cationic detergents with a low CMC condense plasmid DNA into $25 \mathrm{~mm}$ particles and transfect cells in culture. Submitted.

Devaux, P.F., 1991. Static and dynamic lipid asymmetry in cell membranes. Biochemistry 30, 1163-1173.

Eastman, S.J., Siegel, C., Tousignant, J., Smith, A.E., Cheng, S.H., Scheule, R.K., 1997. Biophysical characterization of cationic lipid-DNA complexes. Biochim. Biophys. Acta $1325,41-62$.

Gershon, H., Ghirlando, R., Guttman, S.B., Minsky, A., 1993. Mode of formation and structural features of DNAcationic liposome complexes used for transfection. Biochemistry $32,7143-7151$.

Godbey, W.T., Wu, K.K., Mikos, A.G., 1999. Poly(ethylen- imine) and its role in gene delivery. J. Controlled Release $60,149-160$.

Hirons, G.T., Fawcett, J.J., Crissmann, H.A., 1994. Toto and Yoyo. New very bright fluorochromes for DNA content analysis by flow cyrometry. Cytometry 15, 129-140.

Lasic, D.D., 1997. Liposomes in Gene Delivery. CRC Press, Boca Raton, FL.

Le Pecq, J.-B., Paoletti, C., 1967. A fluorescent complex between ethidium bromide and nucleic acids. J. Mol. Biol. 27, 87-106.

Lentz, B.R., 1989. Membrane 'fluidity' as detected by diphenylhexatriene probes. Chem. Phys. Lipids 50, 171190.

Mel'nikov, S.M., Sergeyev, V.G., Yoshikawa, K., 1995a. Discrete coil-globule transition of large DNA induced by cationic surfactant. J. Am. Chem. Soc. 117, 2401-2408.

Mel'nikov, S.M., Sergeyev, V.G., Yoshikawa, K., 1995 b. Transition of double-stranded DNA chains between random coil and compact globule states induced by cooperative binding of cationic surfactant. J. Am. Chem. Soc. 117, 9951-9956.

Mel'nikov, S.M., Sergeyev, V.G., Yoshikawa, K., 1997. Folding of long DNA chains in the presence of distearylammonium bromide and unfolding induced by neutral liposomes. J. Chem. Soc. Faraday Trans. 93, 283-288.

Mel'nikova, Y.S., Mel'nikov, S.M., Löfroth, J.-E., 1999. Physico-chemical aspects of the interaction between DNA and oppositely charged mixed liposomes. Biophys. Chem. $81,125-141$.

Mernissi-Arifi, K., Zenkouar, M., Schlewer, G., Spiess, B., 1996. Quantitative investigation of the interactions between inositol-tris(phosphates) and polyamines. J. Chem. Soc. Faraday Trans. 92, 3101-3107.

Miller, A.D., 1998. Cationic liposomes for gene therapy. Angew. Chem. Int. Ed. 37, 1768-1785.

Moscho, A., Orwar, O., Chiu, D.T., Modi, B.P., Zare, R.N., 1996. Rapid preparation of giant unilamellar vesicles. Proc. Natl. Acad. Sci. USA 93, 11443-11447.

Pigault, C., Gérard, D., 1984. Influence of location of tryptophanyl residues in proteins on their photosensitivity. Photochem. Photobiol. 40, 291-297.

Pinnaduwage, P., Schmitt, L., Huang, L., 1989. Use of quaternary ammonium detergent in liposome mediated DNA transfection of mouse L-cells. Biochim. Biophys. Acta 985, 33-37.

Rémy, J.-S., Sirlin, C., Vierling, P., Behr, J.-P., 1994. Gene transfer with a series of lipophilic DNA-binding molecules. Bioconjug. Chem. 5, 647-654.

Riddles, P.W., Blakeley, R.L., Zerner, B., 1979. Ellman's reagent: 5,5'-dithiobis(2-nitrobenzoic acid), a reexamination. Anal. Biochem. 94, 75-81.

Roseman, M.A., Thompson, T.E., 1980. Mechanism of the spontaneous transfer of phospholipids between bilayers. Biochemistry 19, 439-444.

Shinitzky, M., Barenholz, Y., 1978. Fluidity parameters of lipid regions determined by fluorescence polarization. Biochim. Biophys. Acta 515, 367-394.

Tang, M.X., Szoka, F.C., 1997. The influence of polymer 
structure on the interactions of cationic polymers with DNA and morphology of the resulting complexes. Gene Ther. 4, 823-832.

Toncheva, V., Wolfert, M.A., Dash, P.R., Oupicky, D., Ulbrich, K., Seymour, L.W., Schacht, E.H., 1998. Novel vectors for gene delivery formed by self-assembly of DNA with poly(L-lysine) grafted with hydrophilic polymers. Biochim. Biophys. Acta 1380, 354-368.

Watts, C., Marsh, M., 1992. What goes in and how. J. Cell Sci. 103, 1-8.
Xu, Y., Szoka, F.C. Jr, 1996. Mechanism of DNA release from cationic liposome/DNA complexes used in cell transfection. Biochemistry 35, 5616-5623.

Zabner, J., Fasbender, A.J., Moninger, T., Poellinger, K.A., Welsh, M.J., 1995. Cellular and molecular barriers to gene transfer by a cationic lipid. J. Biol. Chem. 270, 1899719007.

Zelphati, O., Szoka, F.C. Jr, 1996. Mechanism of oligonucleotide release from cationic liposomes. Proc. Natl. Acad. Sci. USA 93, 11493-11498. 